\title{
Atomic and nano-scale characterization of a 50-year-old hydrated $\mathrm{C}_{3} \mathrm{~S}$ paste
}

\author{
Guoqing Geng ${ }^{\mathrm{a}}$, Rae Taylor ${ }^{\mathrm{a}}$, Sungchul Bae ${ }^{\mathrm{a}}$, Daniel Hernández-Cruz ${ }^{\mathrm{c}}$, \\ David A. Kilcoyne ${ }^{\text {b }}$, Abdul-Hamid Emwas ${ }^{\mathrm{d}}$, Paulo J.M. Monteiro ${ }^{\text {a,* }}$ \\ a Department of Civil and Environmental Engineering, University of California at Berkeley, United States \\ ${ }^{\mathrm{b}}$ Advanced Light Source-Lawrence Berkeley National Laboratory, Berkeley, CA, USA \\ ${ }^{\text {c }}$ Facultad de Ingeniería, Universidad Autónoma de Chiapas, Tuxtla Gutiérrez, Chiapas, México, 29050. \\ ${ }^{d}$ NMR Core lab, King Abdullah University of Science and Technology, 23955,Thuwal, Saudi Arabia
}

\begin{abstract}
This paper investigates both the atomic and nano-scale structure of a 50-year-old hydrated alite $\left(96 \% \mathrm{C}_{3} \mathrm{~S}\right)$ paste. Imaged by SEM, the outer product $\mathrm{C}-\mathrm{S}-\mathrm{H}$ fibers are $1.5-2 \mathrm{~nm}$ thick and can reach several tens nanometers long. ${ }^{29} \mathrm{Si} \mathrm{NMR}$ shows $47.9 \% \mathrm{Q}_{1}$ and $52.1 \% \mathrm{Q}_{2}$, with a mean $\mathrm{SiO}_{4}$ tetrahedron chain length (MCL) of 4.18, indicating a limited degree of polymerization even after 50 years' hydration. Scanning Transmitted X-ray Microscopy (STXM) study was conducted on this late-age paste as well as a 1.5 years old hydrated $\mathrm{C}_{3} \mathrm{~S}$ solution. Near Edge X-ray Absorption Fine Structure (NEXAFS) at $\mathrm{Ca} \mathrm{L}_{3,2}$-edge indicates that $\mathrm{Ca}^{2+}$ in $\mathrm{C}-\mathrm{S}-\mathrm{H}$ is in an irregular symmetric coordination, which agrees more with the atomic structure of tobermorite than that of jennite. At Si K-edge, multi-scattering phenomenon is sensitive to the degree of polymerization, which has the potential to unveil the structure of $\mathrm{SiO}_{4}{ }^{4-}$ tetrahedron chain.
\end{abstract}

Keywords: B: TEM; NMR; Microstructure; D: $\mathrm{Ca}_{3} \mathrm{SiO}_{5}$; STXM

\footnotetext{
*Corresponding author. Tel.: +1 510643 8251; fax: +1 510643 5264. E-mail address: monteiro@ berkeley.edu (P.J.M. Monteiro).
} 


\section{Introduction}

Portland cement is the primary component of modern concrete, and its use in construction continues to increase [1]. Despite decades of research, many questions regarding the hydration and long-term performance of cement-based materials remain unclear. One of the key issues that remain to the resolved is the atomic, nano and micro scale structure of hydration products, particularly calcium silicate hydrates $(\mathrm{C}-\mathrm{S}-\mathrm{H})$. Answers to these questions are critical to improving modern concrete science and technology.

Relevant research is hamstrung by the complexity of the cement-based material, which comes from the heterogeneous nature of the hydration products of ordinary Portland cement (OPC). Alite, or its pure chemical phase tricalcium silicate $\left(3 \mathrm{CaO} \cdot \mathrm{SiO}_{2}\right.$, or, in cement chemistry notation, $\mathrm{C}_{3} \mathrm{~S}$ ), is a major component of OPC and is frequently used to model the hydration system of OPC [2]. However, even when modeling a simple system such as pure $\mathrm{C}_{3} \mathrm{~S}$, the dissolution, diffusion and precipitation processes involved in the hydration process still remains unclear.

For example, the heat generated by $\mathrm{C}_{3} \mathrm{~S}$ hydration shows an induction behavior between the initial heat release (shortly after mixing with water) [5] and accelerated reaction period, which cannot be thoroughly explained by any single hypothesis. Stein [6] was the first researcher to attribute this induction behavior to the rapid formation of a meta-stable calcium silicate hydrate layer, which is thin but still able to prohibit the dissolving of unreacted $\mathrm{C}_{3} \mathrm{~S}$. Thomas [2] has suggested that the slow rate of nucleation on $\mathrm{C}_{3} \mathrm{~S}$ surface could solely account for the phenomena. This hypothesis gives a more robust interpretation of the heat evolution compared to the Avrami model, which is based on random nucleation [7].

If debates in the mechanism of hydration behavior remain unresolved, they pale in comparison to the contentious discussions surrounding the nature of the primary hydration products, calcium silicate hydrates $(\mathrm{C}-\mathrm{S}-\mathrm{H})$. At the atomic scale, Taylor [8] suggested a dreierkette structure based on the natural mineral tobermorite $\left(\mathrm{Ca}_{5} \mathrm{Si}_{6} \mathrm{O}_{16}(\mathrm{OH})_{2} \cdot 4 \mathrm{H}_{2} \mathrm{O}\right)$. Any 
observed high $\mathrm{Ca} / \mathrm{Si}$ atomic ratio in $\mathrm{C}-\mathrm{S}-\mathrm{H}$ could be explained by either a shortening of chain length or the alternation of an additional natural calcium silicate hydrate mineral, jennite $\left(\mathrm{Ca}_{9} \mathrm{Si}_{6} \mathrm{O}_{18}(\mathrm{OH})_{6} \cdot 8 \mathrm{H}_{2} \mathrm{O}\right)$. The NMR [9] study of neat $\mathrm{C}_{3} \mathrm{~S}$ hydration indicates that the mean chain length (MCL) of $\mathrm{SiO}_{4}$ tetrahedral chain is about 2 at early age and 4.76 after 26 years of hydration. Based on Taylor's model, Richardson [10] developed a more explicit model that attempts to explain several experimental observations, such as the alternation of $\mathrm{Ca} / \mathrm{Si}$ ratio and the evolution of MCL during hydration. At the nano-scale, Jennings [11] suggested that the basic construction unit of C-S-H is non-spherical globule whose dimension is around $5 \mathrm{~nm}$. Constantinides and Ulm [12] applied this model successfully to their nano-indentation experiments. The TEM studies of hydrated $\mathrm{C}_{3} \mathrm{~S}$ and pozzolanic material by Richardson [10] and Taylor [13] demonstrated the material exhibiting a layered structure of C-S-H outer product in a hydrated $\mathrm{C}_{3} \mathrm{~S}$ paste.

In this paper, we denote "outer product" as the hydrates that form in the space that was originally occupied by water, and "inner product" as the hydrates that form within the original boundary of $\mathrm{C}_{3} \mathrm{~S}$ and water. As described by Richardson [10], in an 8-year-old $\mathrm{C}_{3} \mathrm{~S}$ paste with water/cement ratio $(w / c)=0.4$ hydrated at $20^{\circ} \mathrm{C}$, large fibrillar outer products $\mathrm{C}-\mathrm{S}-\mathrm{H}(\mathrm{Op} \mathrm{C}-\mathrm{S}-\mathrm{H})$ form in a radial fashion, rooting on the boundary between Op and Ip C-S-H. Each fibril (100-150 nm wide) is composed of a finer substructure also in a fibrillar shape. This substructure is about 3 $\mathrm{nm}$ in its smallest dimension, with the length varying from a few nanometers to many tens of nanometers.

The sample being investigated here is a 50-year-old alite $\left(96 \% \mathrm{C}_{3} \mathrm{~S}\right)$ hydration system with $\mathrm{w} / \mathrm{c}=0.5$. Most research in cement hydration is limited to a three-year window of time [14]. Analysis of hydration periods greater than this are rarely reported or conducted, even though the typical design service life cycle of cementitious material is, on average, 50 years and sometimes 
as long as 100 years. Therefore, analysis of the evolution of cementitious material at very late age is critical to determine its chemical composition, microstructure and macro-performance.

Previous reports of NMR results on late age samples [10][9][14] indicate elongation in MCL. To advance the limited knowledge of the mechanisms governing late-age hydration, the research reported herein analyzed 50-year-old paste using the unique characterizing technique, Scanning Transmission X-ray Microscope (STXM), combined with similar techniques to those described in literature. The STXM combines X-ray microscopic capabilities with Near Edge X-ray Absorption Fine Structure (NEXAFS) spectroscopy, enabling the in-situ investigation of investigation of Si and $\mathrm{Ca}$ coordination environments within the cementitious material. STXM has been proven useful for examining cement hydration [15][16], but this is the first study to utilize sample at late age hydration.

\section{Experimental Methods}

Sample preparation

Synthesized alite $\left(96 \% \mathrm{C}_{3} \mathrm{~S}\right.$ [17]) and distilled water were mixed at w/c=0.5, and cast into a 2inch-long, 0.5-inch-diameter cylindrical mold. For the first three years the sample was stored in saturated $\mathrm{Ca}(\mathrm{OH})_{2}$ water solution at room temperature. After that the sample was kept in a sealed plastic container, cured at room temperature for 47 years. To investigate the evolution of $\mathrm{C}-\mathrm{S}-\mathrm{H}$, a 1.5-year-old sample was also prepared by mixing pure $\mathrm{C}_{3} \mathrm{~S}$ with distilled water at w/c=5.0. Such a high water to cement ratio was used, so that the suspension could be studied by STXM in an insitu way. Hydrated $\mathrm{C}_{3} \mathrm{~S}$ particles were kept in their original morphology.

$X$-ray Diffraction (XRD)

X-ray diffraction was performed with PANalytical X'Pert Pro diffractometer, operating at $40 \mathrm{KeV}$ and $40 \mathrm{~mA}$ with a Cobalt anode. The 2-theta scanning range was between $5^{\circ}$ to $100^{\circ}$, with 
a step width of $0.0167^{\circ}$ and collection time of 0.475 second per step. Software HighScore (Plus) was used to identify the peak positions. Because the sample was stored for 50 years, there was an increased possibility of carbonation. To identify the carbonation status, two powder samples were prepared for the XRD test, one from the surface of the cylinder and the other from the core, denoted respectively as SP (surface part) and CP (core part).

\section{Scanning Electron Microscope (SEM)}

This study used a ZEISS EVO ${ }^{\circledR}$ MA10 SEM, with an Energy Dispersive X-ray Spectrometer (EDX), operated in Secondary Electron (SE) detection mode with high vacuum and accelerating voltage of $20 \mathrm{KV}$. Probe currency was modified to obtain the best image quality. In order to avoid carbonation, only sections of the sample taken from the core were viewed under the SEM. The natural fracture surface of the sample was carbon-coated to prevent sample charging, while various locations were observed to yield a statistically representative result.

\section{${ }^{29}$ Si Magic Angle Spinning Nuclear Magnetic Resonance (MAS-NMR)}

A section of the sample taken from the core was finely ground and packed evenly into a 4$\mathrm{mm}$ zirconia rotor and sealed at the open end with a Vespel cap. The rotor was the spun at $14 \mathrm{kHz}$ on a Bruker Ultrashield 400.13 WB Plus with a 9.2 T magnet operating at $79.495 \mathrm{MHz}$ for ${ }^{29} \mathrm{Si}$ and a dwell time of $10 \mu \mathrm{s}, 2048$ acquisitions were obtained in all cases. In order to obtain quantitative data a recycle delay of 30 seconds was used, which allowed for full relaxation of the signal. The magic angle was set to $54.734^{\circ}$, using $\mathrm{KBr}$ as a reference. The quantitative information on the fractions of silicon ions present in silicate tetrahedra with different connectivities was obtained by deconvolution of the single-pulse spectrum. In this work, the spectrum were fitted by the iterative fitting of the hydrate peaks to Voigt lineshapes using IgorPro 6.35A5 (Wavemetrics, Inc., U.S.A.). 


\section{Transmission Electron Microscope (TEM)}

Fine powders were scraped from the core of the cylinder, and suspended with ethanol. The suspension was then deposited on a carbon film and air-dried for 5 min. Ten-nm-diameter gold particles, coated the carbon film to assure proper alignment of the reconstruction. A Titan CT TEM, equipped with Xplore $3 D$ tomography software was used. To ensure no $\mathrm{Ca}(\mathrm{OH})_{2}(\mathrm{CH})$ particles exist, which will cause strong scattering, the diffraction pattern was investigated before the tomography measurement was conducted. The rotation range was set as 0 to $-65^{\circ}$ and 0 to $+65^{\circ}$, which collected 361 projection images that were then aligned using IMOD software [18].

\section{Scanning Transmission X-ray Microscope (STXM)}

Fine powders extracted from the core of the cylinder were suspended in distilled water, and then a $0.02 \mu \mathrm{l}$ drop was transferred onto a $100 \mathrm{~nm}$ thick silicon nitride window. The window was then attached to a thin steel plate and fixed to the STXM sample stage. As shown in Figure 1, the incidence X-ray beam can be tuned to continuously changing energy level, and the sample stage allows scanning at high spatial resolution; therefore X-ray Absorption Spectra (XAS) can be recorded at specific locations of interest, providing point analysis. By applying a high resolution Fresnel zone plate, the spatial resolution of STXM can reach $25 \mathrm{~nm}$. To study the chemical environmental evolution, a control sample of pure $\mathrm{C}_{3} \mathrm{~S}$, w/c=5.0 with a curing age of 1.5 years, was also studied. The high w/c ratio of the sample was necessary to enable the study of an isolated cement particle under STXM. This would not be possible with a standard w/c ratio, as the particles would clump, resulting in a thick sample, which X-ray could not penetrate. Throughout this study the 50-year-old sample tested by STXM will be referred as $\mathrm{C}_{3} \mathrm{~S} 50$ and the 1.5 -year-old sample will be referred as $\mathrm{C}_{3} \mathrm{~S} 1.5$.

The STXM apparatus is affiliated to Advanced Light Source (ALS) at Lawrence Berkeley National Laboratory (LBNL) at beamline 5.3.2.1 and 5.3.2.2, with an energy scanning ranges of 
700-2200 eV and 250-800 eV, respectively. X-ray absorption spectrum typically records the absorption intensity versus the incident beam energy. An absorption edge is encountered when the incident beam energy is close to the specific energy difference between the inner-shell and outer-shell orbitals in certain atom. Meanwhile, significant absorption is observed due to the excitation of inner-shell electrons to outer-shell orbits. This study focused on a unique part of the $\mathrm{X}$-ray absorption spectra, from about $30 \mathrm{eV}$ before the absorption edge, to $30 \mathrm{eV}$ after the edge, resulting in a whole energy extension of about $60 \mathrm{eV}$. This unique part is named Near Edge X-ray Absorption Fine Structure, shortened as NEXAFS. Specifically, the NEXAFS spectra of calcium (Ca) $\mathrm{L}_{3,2}$-edge, silicon (Si) K-edge and carbon (C) K-edge were studied. They correspond respectively to the excitation of L-shell electrons in $\mathrm{Ca}$ atoms, $\mathrm{K}$-shell electron in $\mathrm{Si}$ atoms and $\mathrm{K}$ shell electron in $\mathrm{C}$ atoms. The NEXAFS spectra are sensitive to the coordination status of the studied atom. Peak-position shift or curve shape changing would be observed when varying atomic environment. The energy resolution can be as high as $0.1-0.2 \mathrm{eV}$. Alteration in the chemical environment of $\mathrm{Ca}$ and $\mathrm{Si}$ will affect their NEXAFS, providing the opportunity to obtain valuable chemical information, e.g. the coordination state or the changes in the neighboring atoms in molecular structure [19][20]. Besides, absorption spectra at carbon K-edge could yield the information of carbonation [34].

STXM data can be collected in several ways: a) Image can be generated from the absorption data of each pixel. In this case, the beam energy is fixed and the scanning is only conducted in spatial dimension. Usually the data is converted to optical density (OD) image through the BeerLamber law: $\mathrm{OD}=-\ln \left[I / I_{0}\right]$, where $I$ is the intensity of the transmitted beam and $I_{0}$ is the incidence beam intensity [21]. A bright area on the OD image indicates a large absorption. Note that the amount of absorption is affected to by three factors: density, thickness and the absorption coefficient. Specially, the absorption coefficient can be largely increased to a significant degree when the incident beam energy reaches the absorption edge of certain elements, as explained 
earlier; b) Line scan data can be obtained by scanning both the incident beam energy (within the range of about $60 \mathrm{eV}$ and centered at the absorption edge) and spatial dimension along a straight line on the sample. Line-scan data contains the NEXAFS spectra of each pixel on that line; and c) A stack scan, which is the most complete scan, measures the NEXAFS on each pixel over the whole image. AXis2000 software is used to process all types of data [22].

\section{Results}

\section{$3.1 X R D$}

In the XRD shown in Figure 2, for both $\mathrm{CP}$ and $\mathrm{SP}$, three phases can be identified, $\mathrm{Ca}(\mathrm{OH})_{2}(\mathrm{CH})$, $\mathrm{C}_{3} \mathrm{~S}$ and $\mathrm{C}-\mathrm{S}-\mathrm{H}$. Unsurprisingly, $\mathrm{CH}$ is the most dominant phase in both plots, since this is the major crystalline hydration product. As would be expected due to its lack of crystallinity, the C$\mathrm{S}-\mathrm{H}$ phase exhibits no sharp peaks on the plots. Instead, a broad peak from $33^{\circ}$ to $38^{\circ}$ can be assigned to the C-S-H structure. With a corresponding spacing of 2.7 to $3.1 \AA$, which confirms the poorly crystallized nature of $\mathrm{C}-\mathrm{S}-\mathrm{H}$ in hardened $\mathrm{C}_{3} \mathrm{~S}$ paste. Similarly broad peaks were observed by Bergold [23], where the C-S-H (alite paste at $23{ }^{\circ} \mathrm{C}$ with w/s $=0.5$ after $65 \mathrm{~h}$ of hydration) peak values are almost identical with those reported herein.

A small peak at $2 \theta=59^{\circ}$ is assigned to $C_{3} S$ [23][24]. The intensity is significantly low so that hydration degree can be concluded to near $100 \%$. Note that there are no peaks that can be assigned to $\mathrm{CaCO}_{3}$. It can be claimed that the paste is not carbonated even after 50 years; this is also supported by the results of the NMR and STXM study, discussed below. In summary, the XRD study proves that, over the span of 50 years almost complete hydration has occurred with zero carbonation. The C-S-H remains poorly crystalline as at the very early age. 
Usually under the secondary electron (SE) mode, different components, such as unreacted $\mathrm{C}_{3} \mathrm{~S}$, Ip C-S-H and Op C-S-H, are less distinguishable. Only under back scattered electron (BSE) mode can they be identified by greyscale value. However, in this 50 -year-old $\mathrm{C}_{3} \mathrm{~S}$ paste sample, SE images show unique features that allow identification of different components (Figure 3).

The SEM results support those indicated by XRD data, in that the sample contained almost no unreacted $\mathrm{C}_{3} \mathrm{~S}$ and no $\mathrm{CaCO}_{3}$. As shown in Figure 3, three features are exposed on the fractural surface: 1) interlaced fibers that form the matrix; 2) globular core with rough surfaces, surrounded by fibrillar matrix; and 3) a crystalline phase in plate-shape. These are identified as Op C-S-H, Ip $\mathrm{C}-\mathrm{S}-\mathrm{H}$ and $\mathrm{CH}$ respectively. The reasoning is as follows: The fibrillar material distributed throughout the whole matrix is oriented in a radial fashion outside the globular core. The thickness of the fibers is approximately 150-250 nm (most fibers are of uniform thickness). Recall that in the early age hydration that fibrillar Op roots on the boundary between Ip and Op C-S-H, in a radial format [14]. When the Op of adjacent $\mathrm{C}_{3} \mathrm{~S}$ particles interlaces with each other, the mixture sets and begins to gain strength. Therefore, the universally existing fibrillar material in the 50-year-old sample most probably comes from the early age fibrillar Op. Because the XRD results determined that the amount of unreacted $\mathrm{C}_{3} \mathrm{~S}$ is negligible, the globular core must be the inner product, containing, most likely, very small amount of $\mathrm{C}_{3} \mathrm{~S}$. Lastly, being the only crystalline phase in the sample, $\mathrm{CH}$ must account for the large plates in the images, whose smooth surface and sharp edge strongly indicate crystalline morphology.

The EDS data were collected at various locations, as shown in Table 1 (the names of these locations are assigned according to the above analysis). The $\mathrm{Ca} / \mathrm{Si}$ ratio of Ip and Op C-S-H is consistent with other studies [25]. Reported $\mathrm{Ca} / \mathrm{Si}$ ratio of $\mathrm{C}-\mathrm{S}-\mathrm{H}$ in pure $\mathrm{C}_{3} \mathrm{~S}$ paste is $\sim 1.7$, which is about the same as the Ip C-S-H ( 1.68), but smaller than the Op C-S-H $(\sim 2.02)$ in this study. The highly observed $\mathrm{Ca} / \mathrm{Si}$ ratio in Op C-S-H indicates a higher $\mathrm{Ca}-\mathrm{OH}$ bonds content in the $\mathrm{Op}$ 
zone. These bonds are either in solid solution state inside C-S-H (as suggested by Richardson [10]) or have formed nanoscale fine crystalline $\mathrm{CH}$ which is too small to be distinguished from C-S-H.

Many researchers have suggested that the Ip is more likely to form in an in-situ reaction pattern, i.e. product forms where reactant is. However, the $\mathrm{Ca} / \mathrm{Si}$ ratio $(\sim 1.68)$ of $\mathrm{Op} \mathrm{C-S-H}$ is much smaller than the original $C_{3} S$. This suggests that, although the Ip is denser than Op [11][12], $\mathrm{Ca}^{2+}$ ions are efficient in migrating to the Op zone. It is worth mentioning that EDS under SE model is more qualitative than quantitative, due to shadowing effect of uneven surface. Besides, the signal comes from $0-3 \mu \mathrm{m}$ beneath the surface, while the material of interests could be only 1 $\mu \mathrm{m}$ thick [26]. But considering the standard deviation, the tendency is reliable as a comparison within this study and other published SEM-EDS results.

\subsection{TEM}

In conducting the TEM measurement, great care was taken in order to find a particle that contained both Ip and Op C-S-H but no $\mathrm{CH}$. The crystal structure of $\mathrm{CH}$ would greatly affect tomographic collection and introduce artifacts. Images of particles at various rotation angles are shown in Figure 4 in series from (a) to (f). Slice images from the 3D acquisition are provided here instead of the 3D reconstruction, this is because there was no single complete data set collected from $-65^{\circ}$ to $65^{\circ}$, without beam damage or the gain moving from view. As a result the missing wedge of the sample largely decreases the resolution of the 3D reconstruction, and therefore in this case $2 \mathrm{D}$ images are better in showing details. As the sample rotates from (a) to (f), one part (area P) of the particle disappears and the other (area Q) appears. We conclude that the observed particle is a conjunction of Op C-S-H (area P) and Ip C-S-H (area Q) with a total dimension of about 150nm. White arrows in Figure 4(b) mark the boundary between Ip and Op C-S-H. The rationale is explained as follows. 
The determination of Ip and Op C-S-H in the image series is based on the TEM morphological observation of $\mathrm{C}_{3} \mathrm{~S}$ pastes obtained from the literature [10][14][27]. The Op C-S-H of $\mathrm{C}_{3} \mathrm{~S}$ paste in previous research always exhibits a fibrillar shape, rooting on the surface of Ip-Op boundary. Although it can alter to foil-like Op C-S-H when the hydration environment is rich in $\mathrm{Ca}^{2+}, \mathrm{Al}^{2+}$ (for instance in the case of $\mathrm{CaCl}_{2}$ or alkali activation / Slag addition [10]), the Op C-S$\mathrm{H}$ in pure $\mathrm{C}_{3} \mathrm{~S}$ paste (and in also $\mathrm{C}_{2} \mathrm{~S}$ paste [10]) is fibrillar all through the hydration process. The diameter seems to grow from several tens of nanometers at very early age to about $100 \mathrm{~nm}$ at eight years old, and eventually to $\sim 200 \mathrm{~nm}$ at 50 -year-old, as indicated by the SEM results in this work.

The Ip C-S-H in this sample, meanwhile, appears to be the aggregation of globular particles. At a finer scale $(<10 \mathrm{~nm})$, the Op C-S-H fibers are composed of large numbers of long thin particles aligned along its length. The particles are about 1.5-2 $\mathrm{nm}$ in their smallest dimension and can be a few nanometers to many tens of nanometers long. Adjacent particles are separated by a transparent layer around $1.5 \mathrm{~nm}$ thick, which is most likely to be water layers when the sample is in moisture [8]. Based on these observations, area $\mathrm{P}$ is considered to be Op C-S-H because of its alternating lamellar structure of long-thin particles and water layer. The thickness of the particle is $1.5-2 \mathrm{~nm}$ and the water layer $1.5 \mathrm{~nm}$, which is in good agreement with Richardson's work on $\mathrm{C}_{3} \mathrm{~S}$ pastes [10].

Area Q has similar morphology as the Ip C-S-H reported in other studies [10][27]. Unlike the fibrillar Op C-S-H, the Ip C-S-H appears to be the aggregation of globular particles. This results in a denser packing than Op. Besides, the texture of Ip is rather homogenous, while that of Op is with a preferred growing direction.

\section{$3.4 N M R$}

To determine the silicon anion structure present in the C-S-H phases, ${ }^{29} \mathrm{Si}$ MAS NMR was used to obtain quantitative information of the fraction of silicon present in different tetrahedral environments. The original spectrum shown in Figure 5 has only two resolvable peaks at shifts of 
-79.0 and $-85.1 \mathrm{ppm}$. Anhydrous $\mathrm{C}_{3} \mathrm{~S}$ contains nine distinctive silicate anion environments, which are represented in a spectrum as five resolvable peaks in the range of around -68 to $-75 \mathrm{ppm}$ [28]. As there is no indication of any peaks in this range, it can be concluded that the $C_{3} S$ was fully reacted, which is in agreement with the results obtained from the XRD. Because the spectrum has zero intensity in the range of -89 to $-103 \mathrm{ppm}$ there are no Si anions in either chain branching sites or three dimensional frameworks $\left(\mathrm{Q}^{3}\right.$ or $\left.\mathrm{Q}^{4}\right)$ that form when pastes carbonate [29], confirming that the C-S-H has not been carbonated, which is also in agreement with XRD results.

From integration of the areas under each deconvoluted peak, it is possible to calculate the percentage of $\mathrm{Si}$ atoms in each environment, and compare this with a sample of $\mathrm{C}_{3} \mathrm{~S}$ over a range of hydration length from 12 hours to 26 years [9]. The results obtained from that study are given in Table 2 with the additions of the MCL. The 50-year-old sample was cured in saturated limewater for three years and then sealed in a plastic bottle. After half-century hydration, the Mean Si tetrahedron Chain Length (MCL) is only 4.18, compared with 2 at 12 hours and 3.27 at 1 year [9]. The polymerization process is so slow, that one can expect within the normal service life time (50 years to 1 century), $\mathrm{C}-\mathrm{S}-\mathrm{H}$ in $\mathrm{C}_{3} \mathrm{~S}$ hydration product would always remain low degree of polymerization.

The results in Table 2 suggest that dimers are formed first from monomers $\left(\mathrm{Q}^{0}\right)$, then longer chains can be formed $\left(\mathrm{Q}^{2}\right)$ from the linking of dimers with monomers, but chains longer than dimers do not form directly from monomers alone. This is verified by the work of Lippmaa et al, who reported a reduction but not a complete halt in monomer consumption and $\mathrm{Q}^{1}$ production during the formation of $\mathrm{Q}^{2}$ units [28]. If $\mathrm{Q}^{2}$ units were formed directly from monomers, the consumption of monomers would most likely increase, as more units are needed in chains than in dimers. The results in the table also show that significant quantities of $\mathrm{Q}^{2}$ units are not formed until a minimal amount of monomers remain. As Lippmaa et al found $\mathrm{Q}^{1}$ production declines 
with initial $\mathrm{Q}^{2}$ production; there is the indication that regardless of the degree of hydration of the paste, $\mathrm{C}_{3} \mathrm{~S}$ systems are not able to form both dimers and longer chain simultaneously.

The formation of $\mathrm{Q}^{2}$ units does not start until over $30 \%$ of anions are present as dimers, once this has occurred the percentage of dimers present never falls below 40\%, even after 40 years; see Taylor et al. [30]. As the method of polymerization is that of linking dimers and monomers, the most likely reason for the discontinuation of dimer consumption in order to form longer chains is the absence of any monomer species at this stage. If this is the case, it would also indicate that dimers cannot link with each other and as such the sequence of chain lengths is possible (3n-1). As observed by TEM, the fine particles in Op C-S-H can be as long as several tens of nanometers, much longer than the MCL (4.18 $\mathrm{SiO}_{4}^{4-}$ tetrahedrons, which is about $1.1 \mathrm{~nm}$ [31]). There is a missing link from this short $\mathrm{SiO}_{4}^{4-}$ tetrahedron chain to the long-thin particle. According to Richardson [10][32], this can be explained by $\mathrm{Ca}^{2+}$ replacing the bridging $\mathrm{SiO}_{4}^{4-}$ tetrahedron in the regular tobermorite structure, or the protonation of oxygen atom that decreases the length of $\mathrm{Si}$ chain. This model explains the phenomena (such as MCL and $\mathrm{Ca} / \mathrm{Si}$ ) but it has been difficult to prove experimentally. The STXM results discussed below provide some new evidence.

\subsection{STXM}

NEXAFS (near edge x-ray absorption fine structure) provides abundant information about bonding and coordination state of absorbing atoms and STXM allows in-situ NEXAFS study at local area of solid material [33]. Multiple factors can affect the fine structure of absorption spectra. Absorption peaks can either be assigned to the excitation of inner-shell electrons to outershell energy levels, or the multi-scattering process of photon-electron interaction. These fine structures are sensitive to the electron structure; e.g., when the degree of polymerization increases, the major peak in Si K-edge increases also. In $\mathrm{Ca} \mathrm{L}_{3,2}$-edge, when the symmetry of coordination is altered, a split in major-absorption peaks can be observed and the difference in the intensity ratio among the peaks can provide qualitative information on the degree of structural distortion. 


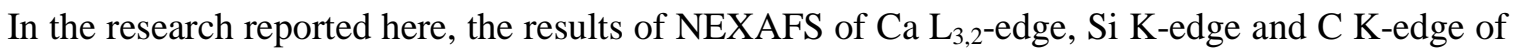
50-year-old hydrated $\mathrm{C}_{3} \mathrm{~S}$ sample $\left(\mathrm{C}_{3} \mathrm{~S} 50\right)$ were studied; a 1.5 year $\mathrm{C}_{3} \mathrm{~S}$ paste $\left(\mathrm{C}_{3} \mathrm{~S} 1.5\right)$ was also studied for comparison.

Ca $L_{3,2}$-edge

STXM results of $\mathrm{Ca}_{3,2}$-edge are shown in Figure 6. Stack data were collected from two particles: (a) $\mathrm{C}_{3} \mathrm{~S} 50$ and (b) $\mathrm{C}_{3} \mathrm{~S} 1.5$. As described in previous section, stack data contain the NEXAFS information of each pixel in the field of view. By comparing the spectra of different area, one can distinguish between various components. The hydrated particles in Figure 6a were not damaged during sample preparation, enabling in-situ observation. Through investigating the NEXAFS spectra of each pixels of the whole image, two representative spectra were extracted, as shown in Figure 6c. One was collected from site 1, a margin area of a particle in Figure 6a, and the other from site 2 on a bulk particle. In Figure $6 \mathrm{~b}$, two representative spectra were also extracted, after examining spectra of each local area in the field of view.

The $\mathrm{Ca}_{3,2}$-absorption edge spectra corresponds to the excitation from $\mathrm{Ca} 2 \mathrm{p}$ to $3 \mathrm{~d}$ orbitals. Two major peaks (X1 and Y1) can always be observed due to of the loss of degeneracy of $2 \mathrm{p}$ orbitals by spin-orbital interaction [36]. Despite the chemical status of $\mathrm{Ca}$, these two major peaks are observed in the $\mathrm{L}_{3,2}$-edge spectra of most Ca-containing minerals. The symmetry of $\mathrm{CaO}_{\mathrm{x}}$ coordination complex could further break the degeneracy of states, resulting in two minor peaks to the left of major ones. This phenomena was well explained by crystal field theory, which was later combined with molecular orbital theory and developed to ligand field theory [36]. In case of perfect octahedral symmetry, two major peaks are strongly splitted so that the intensity of the minor peaks are comparable to those of the major peaks. Besides, the energy differences between major and minor peaks are also significant. These two characters can be used to indicate the strength of the crystal field of $\mathrm{CaO}_{\mathrm{x}}$ complex. 
Table 3 classifies the Ca coordination status into two categories based on their coordination symmetry. When the coordination is in octahedral symmetry (or near octahedral symmetry), such as the case of $\mathrm{CH}$, calcite and dolomite, the spectra will be strongly affected by "crystal field" effect. Significant splitting in major peaks $\mathrm{X} 1$ and $\mathrm{Y} 1$ is allowed, and strong minor peaks $\mathrm{X} 2$ and Y2 could be observed in this case. The energy difference between adjacent major and minor peaks is 1.2 1.4 eV. Spectra of $\mathrm{CH}$ is shown in Figure 6c. Examples of calcite and dolomite can be found in [36][37]. Meanwhile in aragonite and gypsum, the coordination symmetry of $\mathrm{Ca}$ is rather irregular, which is considered to be a "weak crystal field". In this case, 3d orbital is less degenerated and minor peaks (X2 and Y2) change in two ways: they decrease in intensity, and they shift to higher energy. This makes the minor peaks less distinguishable on the NEXAFS spectra, as well as shorten the distance between major and minor peaks. This observation, verified by study of many minerals, can therefore be applied to the interpretation of Ca coordination status in $\mathrm{C}-\mathrm{S}-\mathrm{H}$ and $\mathrm{CH}$.

$\mathrm{C}-\mathrm{S}-\mathrm{H}$ and $\mathrm{CH}$ are the two main hydration products. $\mathrm{Ca}$ in $\mathrm{CH}$ is in perfect octahedral symmetry and a strong splitting is observed in its $\mathrm{L}_{3,2}$-edge spectra, as shown in Figure 6c. Energy difference between major and adjacent minor peak is $\sim 1.4 \mathrm{eV} . \mathrm{L}_{3,2}$-edge spectra of C-S-H was also reported in earlier literatures [15][35], which exhibited weak splitting. In Figure 6, spectra of site 1 in both samples exhibit weak splitting, with energy difference between major and minor peaks of $0.9-1.1 \mathrm{eV}$, while energy differences on spectra of site 2 in both samples are $\sim 1.3$ $\mathrm{eV}$. Therefore we assign site 1 in to $\mathrm{C}-\mathrm{S}-\mathrm{H}$-rich region and site 2 to $\mathrm{CH}$-rich region. Also from a morphological point of view, site 1 in Figure 6a locates on fibrillar margin area of hydrated particle, resembling the morphology of Op C-S-H. In Figure 6b, not much morphological information is evident, since the grinding process largely altered the microstructure.

The small energy difference and the low intensity of minor peaks, of C-S-H in both $\mathrm{C}_{3} \mathrm{~S} 50$ and $\mathrm{C}_{3} \mathrm{~S} 1.5$, are similar with the spectra of aragonite and gypsum, as shown in Table 3 . The 
relative weak crystal field effect in C-S-H indicates poor symmetry of Ca coordination structure. Spectra of $\mathrm{Ca}$ in $\mathrm{CH}$ of both samples share the same feature with spectra of pure $\mathrm{CH}$, as well as calcite and dolomite [36]. It's worth pointing out that the major peaks X2 and Y2 are consistent among all spectra. Changing of chemical environment seems to be solely indexed by intensity and energy values of minor peaks.

\section{Si K-edge}

STXM results at Si K-edge are shown in Figure 7. Since Si K-edge has a higher absorption energy (compared to $\mathrm{Ca}_{3,2}$-edge) and therefore ensures greater penetration depth, resulting in more morphological details under microscope in the absorption images. In $\mathrm{C}_{3} \mathrm{~S} 1.5$ (Figure 7(a) and (b)), fibrillar Op C-S-H covers the surface of $\mathrm{C}_{3} \mathrm{~S}$ particles, while the core area appears to be featureless. In $\mathrm{C}_{3} \mathrm{~S} 50$ ((c) and (d)), the morphology is not well retained after sample preparation.

Absorption at Si K-edge has only a single absorption edge with no splitting. A designation of the major peak as $\mathrm{X}$ and the minor peak as $\mathrm{Y}$ in Figure $7 \mathrm{e}$ is given. The major peak is due to excitation from 1 s orbital to $3 p$ orbital and minor peaks are due to multi-scattering phenomena [38][39]. Both peaks shift to higher energy along with the hydration process. Li et al. [38] reported that major peak $\mathrm{X}$ shifts to higher energy when the degree of polymerization increases, which is in good agreement with the results of this study. Peak X of C-S-H gel in 1.5-year-old sample locates at $1848.1 \mathrm{eV}, 0.4 \mathrm{eV}$ higher than that of anhydrous $\mathrm{C}_{3} \mathrm{~S}$. At 50 years, it changes to $1848.3 \mathrm{eV}$. As the degree of polymerization increases, energy level of Si 1s orbital decreases, which increasing the excitation energy. Note that the change is not high, suggesting that $\mathrm{Si}$ is always in 4-fold tetrahedron coordination in $\mathrm{C}_{3} \mathrm{~S}$ hydration system.

The minor peak $\mathrm{Y}$ also increases with hydration at a higher rate compared to that of peak $\mathrm{X}$, so that the energy difference, $\Delta \mathrm{E}$, between peak $\mathrm{X}$ and $\mathrm{Y}$ increases. As shown in Table 4, the hydration reaction increases $\Delta \mathrm{E}$ from $11.2 \mathrm{eV}\left(\mathrm{C}_{3} \mathrm{~S}\right)$ up to $12.8 \sim 13.0 \mathrm{eV}$ (1.5-year-old), and 
eventually to $16.5 \mathrm{eV}$ at later age (50-year-old), indicating significant alternation in multiscattering behavior around Si atoms. According to the NMR study, the MCL is about 4.2, compared with $\sim 3.5$ at 1.5 year. The multi-scattering phenomenon is affected by the closest several neighboring atoms, and seems fairly sensitive to the degree of polymerization. An increase in the MCL increases by 0.7 results in an increase in the $\Delta \mathrm{E} 3.5 \mathrm{eV}$. It is not fully understood how the atomic structure changes the multi-scattering behavior. More work is worth doing if this linear relationship holds for various hydration age of C-S-H. Future research will focus on the multi-scattering behavior, and how it is related to the atomic structure, especially the $\mathrm{SiO}_{4}{ }^{4-}$ linkage of C-S-H.

C K-edge

To complement the carbonation study of $\mathrm{C}_{3} \mathrm{~S} 50$, the NEXAFS spectra of Carbon at K-edge was investigated, as shown in Figure 8 (a). A line scan was conducted crossing the border of a gel cluster, as marked by the red arrow. The absorption spectrum of each pixel on the arrow was recorded by line scan. Spectra of a thin area at location $b$ and a slightly thicker area at location $a$ were shown in Figure 8 (b). If the sample were significantly carbonated, two distinguishable peaks would be expected near $285.0 \mathrm{eV}$ and $290.0 \mathrm{eV}$ [34]. On the contrary, the spectra of both location $a$ and $b$ exhibit no obvious peak near $285.0 \mathrm{eV}$ and only a weak peak at $290.2 \mathrm{eV}$, whose intensity is of the same order as the noise of the spectra. Comparing with the unambiguous peaks of carbonated C-S-H gel [34], it could be concluded that the sample contains negligible amount of carbon, in agreement with NMR and XRD.

\section{Discussion}

Results obtained from both XRD and NMR studies indicate that the 50-year-old paste has not been altered by carbonation. No peak seen on either the diffraction spectra or the ${ }^{29} \mathrm{Si}$ NMR spectrum can be assigned to $\mathrm{CaCO}_{3}$. From the chemical composition point of view, the sample is 
merely a mixture of $\mathrm{C}-\mathrm{S}-\mathrm{H}, \mathrm{CH}$ with negligible amount of unreacted $\mathrm{C}_{3} \mathrm{~S}$. NEXAFS spectra of carbon K-edge support this conclusion, as no specific absorption of carbon atom was observed.

In XRD results, only one broad peak is assigned to $\mathrm{C}-\mathrm{S}-\mathrm{H}$ in this study. Compared with previous research on calcium silicate hydrate crystals [32] and synthesized C-S-H (I) [8], the hydration products (both Ip and Op) remain disordered along all three-crystal axes, even after 50 years curing. Meanwhile the MCL remains below 5, despite almost full hydration. This indicates that at ambient temperature and pressure, the poorly crystalline nature of $\mathrm{C}-\mathrm{S}-\mathrm{H}$ gel almost remains unchanged throughout concrete's typical service life.

Many researchers have discussed atomic models of C-S-H gel, most starting with the structures of tobermorite or jennite [32]. The amorphous nature is accounted by the omission of bridging tetrahedrons and the variation of interlayer $\mathrm{Ca}$ and water. However, no direct evidence was previously given as to which structure fits $\mathrm{C}-\mathrm{S}-\mathrm{H}$ gel better. In this study, an important clue was found in the NEXAFS spectra.

As shown in Figure 6 and Table 3, C-S-H falls into the category of aragonite and gypsum, where the coordination structure of $\mathrm{Ca}$ is in poor symmetry. As shown in Figure 9, the coordination structure of $\mathrm{Ca}$ is 7-fold in tobermorite and 6-fold in jennite Figure 9. The latter has an octahedral symmetry, as is found for $\mathrm{Ca}$ in $\mathrm{CH}$ and calcite. If the modeling of $\mathrm{C}-\mathrm{S}-\mathrm{H}$ gel starts with jennite, it should be expected that its NEXAFS spectra is analogous to $\mathrm{CH}$ and calcite. The NEXAFS spectra of Al-tobermorite were validated by Jackson et al. [16], exhibiting minor peaks that are less intensive and less distinguishable. Therefore, the Ca coordination in atomic structure of $\mathrm{C}-\mathrm{S}-\mathrm{H}$ in this sample can be better described by tobermorite structure rather than jennite structure. This is the first time NEXAFS spectra is applied to demonstrating that at atomic scale $\mathrm{C}-\mathrm{S}-\mathrm{H}$ resembles more of tobermorite structure where $\mathrm{Ca}$ atom has irregularity in its symmetry. As reported herein, this is important evidence unraveling the structural information of C-S-H, 
since the relation between coordination symmetry and NEXAFS has been proved by both theory and experimental results of many other chemicals [20][36][37].

The tobermorite model has a limitation in explaining the $\mathrm{Ca} / \mathrm{Si}$ ratio of $\mathrm{C}-\mathrm{S}-\mathrm{H}$. Richardson [10] demonstrated in his model that $\mathrm{Ca} / \mathrm{Si}$ ratio of tobermorite can be largely increased by a variation in the degree of protonation or by $\mathrm{Ca}$ replacing the bridging $\mathrm{SiO}_{4}{ }^{4-}$-tetrahedron. These bridging $\mathrm{Ca}$ ions also contribute to NEXAFS spectra; therefore they must also be in poorly symmetric coordination, for example the 7-fold irregular symmetry as seen in the intralayer $\mathrm{Ca}$ sheets in tobermorite (Figure 10). Due to the same reason, "tobermorite-Ca( $\mathrm{OH})_{2}$ solid solution" model seems questionable, since the octahedral coordinated $\mathrm{Ca}$ atoms in $\mathrm{Ca}(\mathrm{OH})_{2}$ would yield a strong peak-splitting, which is not the case for C-S-H.

Previous research results using SAXS (small angle x-ray scattering) and SANS (small angle neutron scattering) [42] strongly indicate that there exists two successive levels of organization in C-S-H gel (Ip and Op) of OPC. At atomic level $(<5 \mathrm{~nm})$, disordered Si chains, Ca sheets and water layers form nano particles. Jennings [11] claims this particle to be globular particle of about $5 \mathrm{~nm}$. In contrast, Richardson's results [10] indicate it to be long thin fibers of 2.5-3.5 nm thick and tens of nanometers long. It should be clarified that Richardson's observations quoted here focuses on the fibrillar Op C-S-H of pure $\mathrm{C}_{3} \mathrm{~S}$ paste, while Jennings' results are based on homogenized information of various types of C-S-H paste. Despite the shape of the particles, they are the "building blocks" of C-S-H. At a coarse level (5-200nm), the fine particles form the microstructure of C-S-H. Using pure $\mathrm{C}_{3} \mathrm{~S}$ paste as an example, the Op C-S-H fibers are formed by the alignment of the long-thin particles along their longitudinal direction. The featureless microstructure of Op C-S-H in $\mathrm{C}_{3} \mathrm{~S}$ paste can be described by the packing of globular particles (several nanometers large). Given the fact that the $\mathrm{C}_{3} \mathrm{~S}$ in this study comes from different source compared to Richardson's work, and that the age is also different, it can be concluded that these long-thin particles are naturally the basic building blocks of fibrillar Op C-S-H in $\mathrm{C}_{3} \mathrm{~S}$ paste. The 
dimension of these particles and the way they are aligned do not change during the hydration process. The thickening of the Op C-S-H fibers is accomplished by more long-thin particles aligning on the fiber, rather than thickening of the particles. However, these particles can alter significantly when the contents of $\mathrm{Ca}^{2+}$ and $\mathrm{Al}^{3+}$ increase in the reaction system. Increasing amounts of mineral admixture (fly ash, slag, natural pozzolan, silica fume, and so on) are now used as supplementary cementitious material. It is thus critical to understand the mechanism of how $\mathrm{SiO}_{4}^{4-}$ tetrahedron and $\mathrm{Ca}^{2+}$ form the fine particles and why these particles keep a constant size during the hydration, and the mechanism how the addition of $\mathrm{Ca}^{2+}$ and $\mathrm{Al}^{3+}$ favors the formation of globular particles rather than long-thin particles in pure $\mathrm{C}_{3} \mathrm{~S}$ paste. As the dominant binding material, the formation of C-S-H is extremely important. Understanding the above mechanisms can enlighten the development of high-efficiency chemical/mineral admixture and design of high-performance concrete.

\section{Conclusions}

A multi-scale analysis was conducted that compared the structure of a late-age $\mathrm{C}_{3} \mathrm{~S}$ paste to similar paste at earlier age. No evidence of carbonation was observed in the 50-year-old sample; unreacted $\mathrm{C}_{3} \mathrm{~S}$ was also rare. The atomic structure of the late-age C-S-H gel can be described as repeated units of $\mathrm{SiO}_{4}{ }^{4-}$ tetrahedron, $\mathrm{CaO}_{x}$ polyhedron and $\mathrm{H}_{2} \mathrm{O}$ molecules. Even after 50 years of hydration, the structure was still ordered only at short length. The coordination state of $\mathrm{Ca}^{2+}$ has irregular symmetry, rather than octahedral symmetry. Since $\mathrm{Ca}^{2+}$ in tobermorite shows 7-fold irregular symmetry compared to jennite that has an octahedral symmetry, the short-range atomic scale of the samples is more an analogy to that of tobermorite rather than jennite. The MCL increased along with degree of hydration, from $\sim 3.5$ at 1.5 years to 4.18 at 50 years. It is possible that the bridging $\mathrm{SiO}_{4}{ }^{4-}$ tetrahedron is replaced by bridging $\mathrm{Ca}^{2+}$ at multi locations, which explains both the short chain length and $\mathrm{Ca} / \mathrm{Si}$ ratio. The bridging $\mathrm{Ca}^{2+}$ is also in non-octahedral symmetry, 
as indicated by $\mathrm{Ca}_{3,2}$-edge NEXAFS. In Si K-edge, major peak shifts to higher energy with increasing MCL, and so does the minor peak.

At nano scale, Ip C-S-H is featureless and seems to be the flocculation of globular particles. In contrast, Op C-S-H showed clear radial growing fashion, rooting on surface of Ip-Op boundary. Thickness of Op C-S-H fibers increase along with hydration, from several tens of nanometers, to $\sim 100 \mathrm{~nm}$ at 8 years and eventually to $\sim 200 \mathrm{~nm}$ at 50 years. The fiber was composed, at a finer scale, of thin fibrillar particles (1.5-2 nm thick and several tens of nanometers long). These particles are the basic building blocks of Op fibers and tend to align along longitudinal direction. Between the fibrillar particles there exist layers of empty space with thickness of about $1.5 \mathrm{~nm}$, which could be filled with water before sample was dried out. Considering such a narrow space, they are most probably physically absorbed water. The growth of Op fibers is accomplished by more particles aligned on the fibers, instead of the thickening of the particles themselves.

\section{Acknowledgements}

Guoqing GENG's study and research in UC Berkeley are supported by Chinese Scholarship Council (file No. 201206090127). The authors thank Timothy Teague for the technical help with SEM and XRD experiments. This research is funded by the Republic of Singapore's National Research Foundation through a grant to the Berkeley Education Alliance for Research in Singapore (BEARS) for the Singapore-Berkeley Building Efficiency and Sustainability in the Tropics (SinBerBEST) Program. BEARS has been established by the University of California, Berkeley as a center for intellectual excellence in research and education in Singapore. The Advanced Light Source is supported by the Director, Office of Science, Office of Basic Energy Sciences, of the U.S. Department of Energy under Contract No. DE-AC02-05CH11231. 


\section{References}

[1] P. K. Mehta, P. J. Monteiro. Concrete Microstructure, Properties, and Materials. McGrawHill Companies, New York City, Fourth edition, 2014, pages: 641-652.

[2] Jeffrey J. Thomas. "A new approach to modeling the nucleation and growth kinetics of tricalcium silicate hydration.” Journal of the American Ceramic Society 90.10 (2007): 32823288.

[3] Bullard, Jeffrey W., Hamli M. Jennings, Richard A. Livingston, Andre Nonat, George W. Scherer, Jeffrey S. Schweitzer, Karen L. Scrivener, and Jeffrey J. Thomas. "Mechanisms of cement hydration.” Cement and Concrete Research 41.12 (2011): 1208-1223.

[4] D. A. Silva, P. J. Monteiro. "Hydration evolution of $\mathrm{C}_{3} \mathrm{~S}-\mathrm{EVA}$ composites analyzed by soft X-ray microscopy.” Cement and Concrete Research 35.2 (2005): 351-357.

[5] Jeffrey J. Thomas, Andrew J. Allen, and Hamlin M. Jennings. "Hydration kinetics and microstructure development of normal and $\mathrm{CaCl}_{2}$-accelerated tricalcium silicate pastes." The Journal of Physical Chemistry C 113.46 (2009): 19836-19844.

[6] H. N. Stein, Stevels J. M. "Influence of silica on the hydration of $3 \mathrm{CaO} \cdot \mathrm{SiO}_{2}$." Journal of Applied Chemistry 14.8 (1964): 338-346.

[7] M. Avrami. "Kinetics of phase change. I General theory", The Journal of Chemical Physics, 7.12 (1939), 1103-1112.

[8] Harry F. W. Taylor. Cement chemistry. Thomas Telford, 1997.

[9] S.A. Rodger, G.W. Groves, N.J. Clayden, C.M. Dobson, "Hydration of Tricalcium Silicate Followed by ${ }^{29}$ Si NMR with Cross-Polarization", Journal of the American Ceramic Society, $71(1988)$ 91-96.

[10] I. G. Richardson. “Tobermorite/jennite-and tobermorite/calcium hydroxide-based models for the structure of C-S-H: applicability to hardened pastes of tricalcium silicate, $\beta$-dicalcium 
silicate, Portland cement, and blends of Portland cement with blast-furnace slag, metakaolin, or silica fume.” Cement and Concrete Research 34.9 (2004): 1733-1777.

[11] Hamlin M. Jennings. "Refinements to colloid model of C-S-H in cement: CM-II." Cement and Concrete Research 38.3 (2008): 275-289.

[12] Georgios Constantinides, Franz-Josef Ulm. "The nanogranular nature of C-S-H.” Journal of the Mechanics and Physics of Solids 55.1 (2007): 64-90.

[13] R. Taylor. Characterization of C-S-H in early and late age systems containing admixtures. Diss. University of Leeds, 2010.

[14] R. Taylor, I. G. Richardson, R. M. D. Brydson. "Composition and microstructure of 20-yearold ordinary Portland cement-ground granulated blast-furnace slag blends containing 0 to 100\% slag." Cement and Concrete Research 40.7 (2010): 971-983.

[15] J. Ha, S. Chae, K. W. Chou, T. Tyliszczak, and P. J. M. Monteiro. "Effect of polymers on the nanostructure and on the carbonation of calcium silicate hydrates: a scanning transmission $\mathrm{X}$ ray microscopy study.” Journal of Materials Science 47.2 (2012): 976-989.

[16] Jackson, Marie D., Sejung R. Chae, Sean R. Mulcahy, Cagla Meral, Rae Taylor, Penghui Li. "Unlocking the secrets of Al-tobermorite in Roman seawater concrete." American Mineralogist 98.10 (2013): 1669-1687.

[17] P. K. Mehta, D. Pirtz, M. Polivka. "Properties of alite cements." Cement and concrete research 9.4 (1979): 439-450.

[18] J.R. Kremer, D.N. Mastronarde, J.R. McIntosh, "Computer visualization of three-dimensional image data using IMOD”, Journal of Structural Biology, 116 (1996) 71-76.

[19] Li, Dien, G. M. Bancroft, Masoud Kasrai, M. E. Fleet, X. H. Feng, K. H. Tan, and B. X. Yang. "High-resolution Si K-and $\mathrm{L}_{2,3}$-edge XANES of $\alpha$-quartz and stishovite." Solid State Communications 87.7 (1993): 613-617.

[20] Naftel, S. J., T. K. Sham, Y. M. Yiu, and B. W. Yates. "Calcium L-edge XANES study of some calcium compounds." Journal of synchrotron radiation 8.2 (2001): 255-257. 
[21] Hernández-Cruz, Daniel, Craig W. Hargis, Sungchul Bae, Pierre A. Itty, Cagla Meral, Jolee Dominowski, Michael J. Radler, David A. Kilcoyne, and Paulo JM Monteiro. "Multiscale characterization of chemical-mechanical interactions between polymer fibers and cementitious matrix." Cement and Concrete Composites (2014).

[22] Image and spectra visualization and analysis, <http://unicorn.mcmaster.ca/aXis2000.html>.

[23] S. T. Bergold, F. Goetz-Neunhoeffer, J. Neubauer. "Quantitative analysis of C-S-H in hydrating alite pastes by in-situ XRD.” Cement and Concrete Research 53 (2013): 119-126.

[24] Courtial, Mireille, M-N. De Noirfontaine, Frederic Dunstetter, Gilles Gasecki, and Marcel Signes-Frehel. "Polymorphism of tricalcium silicate in Portland cement: a fast visual identification of structure and superstructure.” Powder Diffraction18.01 (2003): 7-15.

[25] Thomas, Jeffrey J., Jeffrey J. Chen, Hamlin M. Jennings, and Dan A. Neumann. "Ca-OH bonding in the C-S-H gel phase of tricalcium silicate and white portland cement pastes measured by inelastic neutron scattering." Chemistry of materials 15.20 (2003): 3813-3817.

[26] Karen L. Scrivener. "Backscattered electron imaging of cementitious microstructures: understanding and quantification." Cement and Concrete Composites 26.8 (2004): 935-945.

[27] Geoffrey W. Groves. "TEM studies of cement hydration." MRS proceedings. Vol. 85. Cambridge University Press, 1986.

[28] E. Lippmaa, M. Mägi, M. Tarmak, W. Wieker, A.R. Grimmer, “A high resolution ${ }^{29}$ Si NMR study of the hydration of tricalciumsilicate", Cement and Concrete Research, 12 (1982) 597 602.

[29] G.W. Groves, A. Brough, I.G. Richardson, C.M. Dobson, "Progressive Changes in the Structure of Hardened $\mathrm{C}_{3} \mathrm{~S}$ Cement Pastes due to Carbonation", Journal of the American Ceramic Society, 74 (1991) 2891-2896.

[30] H. Taylor, P. Barret, P. Brown, D. Double, G. Frohnsdorff, V. Johansen, D. MénétrierSorrentino, I. Odler, L. Parrott, J. Pommersheim, M. Regourd, J. Young, "The hydration of tricalcium silicate, Materials and Structures”, 17 (1984) 457-468. 
[31] Hamlin M. Jennings. "A model for the microstructure of calcium silicate hydrate in cement paste." Cement and Concrete Research 30.1 (2000): 101-116.

[32] I. G. Richardson. "The calcium silicate hydrates." Cement and Concrete Research 38.2 (2008): 137-158.

[33] Chae, Sejung R., Juhyuk Moon, Seyoon Yoon, Sungchul Bae, Pierre Levitz, Robert Winarski, and Paulo JM Monteiro. "Advanced nanoscale characterization of cement based materials using x-ray synchrotron radiation: a review.” International Journal of Concrete Structures and Materials 7.2 (2013): 95-110.

[34] Monteiro, Paulo J M, Laurence Clodic, Francesco Battocchio, Waruntorn Kanitpanyacharoen, Sejung Rosie Chae, Juyoung Ha, and Hans-Rudolf Wenk. "Incorporating carbon sequestration materials in civil infrastructure: A micro and nano-structural analysis." Cement and Concrete Composites 40 (2013): 14-20.

[35] Ha, J., S. Chae, K. W. Chou, T. Tyliszczak, and P. JM Monteiro. "Scanning Transmission XRay Microscopic Study of Carbonated Calcium Silicate Hydrate.” Transportation Research Record: Journal of the Transportation Research Board 2142.1 (2010): 83-88.

[36] Michael E. Fleet, Xiaoyang Liu. "Calcium L2, 3-edge XANES of carbonates, carbonate apatite, and oldhamite (CaS).” American Mineralogist94.8-9 (2009): 1235-1241.

[37] Hanhan, S., A. M. Smith, M. Obst, and A. P. Hitchcock. "Optimization of analysis of soft Xray spectromicroscopy at the Ca $2 p$ edge.” Journal of Electron Spectroscopy and Related Phenomena173.1 (2009): 44-49.

[38] Dien Li, et al. "Silicon K-edge XANES spectra of silicate minerals." Physics and Chemistry of Minerals 22.2 (1995): 115-122.

[39] Dien Li, G. M. Bancroft, M. Kasrai, M. E. Fleet, R. A. Secco, X. H. Feng, K. H. Tan, and B. X. Yang. "X-ray absorption spectroscopy of silicon dioxide $\left(\mathrm{SiO}_{2}\right)$ polymorphs: The structural characterization of opal” American Mineralogist 79 (1994): 622-632. 
[40] Stefano Merlino, Elena Bonaccorsi, and Thomas Armbruster. "Tobermorites: Their real structure and order-disorder (OD) character.” American Mineralogist84 (1999): 1613-1621.

[41] E. Bonaccorsi, S. Merlino, and H. F. W. Taylor. "The crystal structure of jennite, $\mathrm{Ca}_{9} \mathrm{Si}_{6} \mathrm{O}_{18}$ $(\mathrm{OH})_{6.8} \mathrm{H}_{2} \mathrm{O} . "$ Cement and Concrete Research 34.9 (2004): 1481-1488.

[42] Brisard, Sebastien, Rosie S. Chae, Isabelle Bihannic, Laurent Michot, Peter Guttmann, Jürgen Thieme, Gerd Schneider, Paulo JM Monteiro, and Pierre Levitz. "Morphological quantification of hierarchical geomaterials by X-ray nano-CT bridges the gap from nano to micro length scales.” American Mineralogist 97.2-3 (2012): 480-483.

[43] Andrew J. Allen, Jeffrey J. Thomas, and Hamlin M. Jennings. "Composition and density of nanoscale calcium-silicate-hydrate in cement.” Nature materials 6.4 (2007): 311-316.

[44] Sungchul Bae. Synchrotron X-ray Spectro-microscopy and Micro-diffraction Study on the Hydration of Tricalcium Silicate including High-Volume Fly Ash. Diss. University of California Berkeley, 2014. 


\section{Figure Captions:}

Figure 1: Schematic diagram of STXM

Figure 2: XRD results of $\mathrm{CP}$ (core of the cylinder) and SP (surface of the cylinder)

Figure 3: Secondary electron image on different locations in CP (core of the cylinder),

bar length $1 \mu \mathrm{m}$

Figure 4: A series of slices from the reconstruction of a particle in $\mathrm{C}_{3} \mathrm{~S}$ paste, which is unidirectionally rotated from (a) to (f); bar length is $20 \mathrm{~nm}$. Area P and Q are, respectively Op and Ip C-S-H respectively. During rotation the feature of area Q increases while that of area $\mathrm{P}$ fades.

Figure 5: ${ }^{29} \mathrm{Si}$ NMR spectrum of 50-year-old $\mathrm{C}_{3} \mathrm{~S}$ paste, deconvoluted to $\mathrm{Q}^{1}(-79.0)$ and $\mathrm{Q}^{2}(-85.1)$. All y-axis are set to the same intensity.

Figure 6: $\mathrm{Ca}_{3,2}$-edge, scale bar length 500nm: absorption image of (a) $\mathrm{C}_{3} \mathrm{~S} 1.5$ and (b) $\mathrm{C}_{3} \mathrm{~S} 50$; (c) NEXAFS spectra of hydrated C3S samples, compared with that of pure $\mathrm{CH}$. spectra of $\mathrm{CH}$ is from [44].

Figure 7: Si K-edge, scale bar length $1 \mu \mathrm{m}$ : (a) (b) absorption image of $\mathrm{C}_{3} \mathrm{~S} 1.5$; (c) (d) absorption image of $\mathrm{C}_{3} \mathrm{~S} 50$; (e) NEXAFS spectra of various locations.

Figure 8: C K-edge, scale bar length $1 \mu \mathrm{m}$ : (a) absorption image, red arrow indicates the route of line scan; (b) NEXAFS spectra of location $a$ and $b$ on the scan route.

Figure 9: Atomic structure of $11 \AA ̊$-Tobermorite and Jennite [43][44]

Figure 10: Scheme of short chain in tobermorite-based C-S-H 


\section{Table Captions:}

Table 1: Statistics of EDS data of the 50-year-old $\mathrm{C}_{3} \mathrm{~S}$ paste

Table 2: Quantity of Si anions in each environment as a percentage obtained from integration of the peak areas. Data from 12 hours to 26 years are from Rodger [9]

Table 3: Peak characters from the Ca L-edge spectra, some data are from [39][40]

Table 4: Energy difference, $\Delta \mathrm{E}$, between minor and major peak at Si K-edge 
Figures

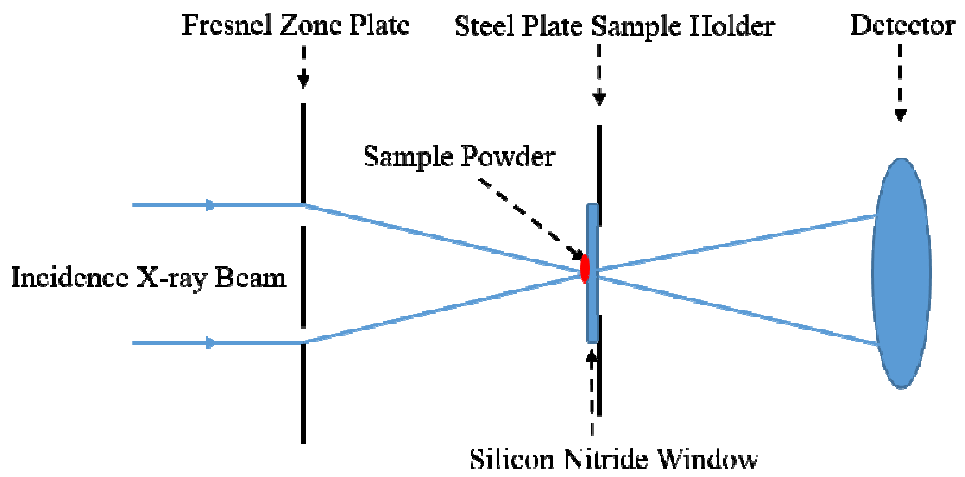

Figure 1: Schematic diagram of STXM 

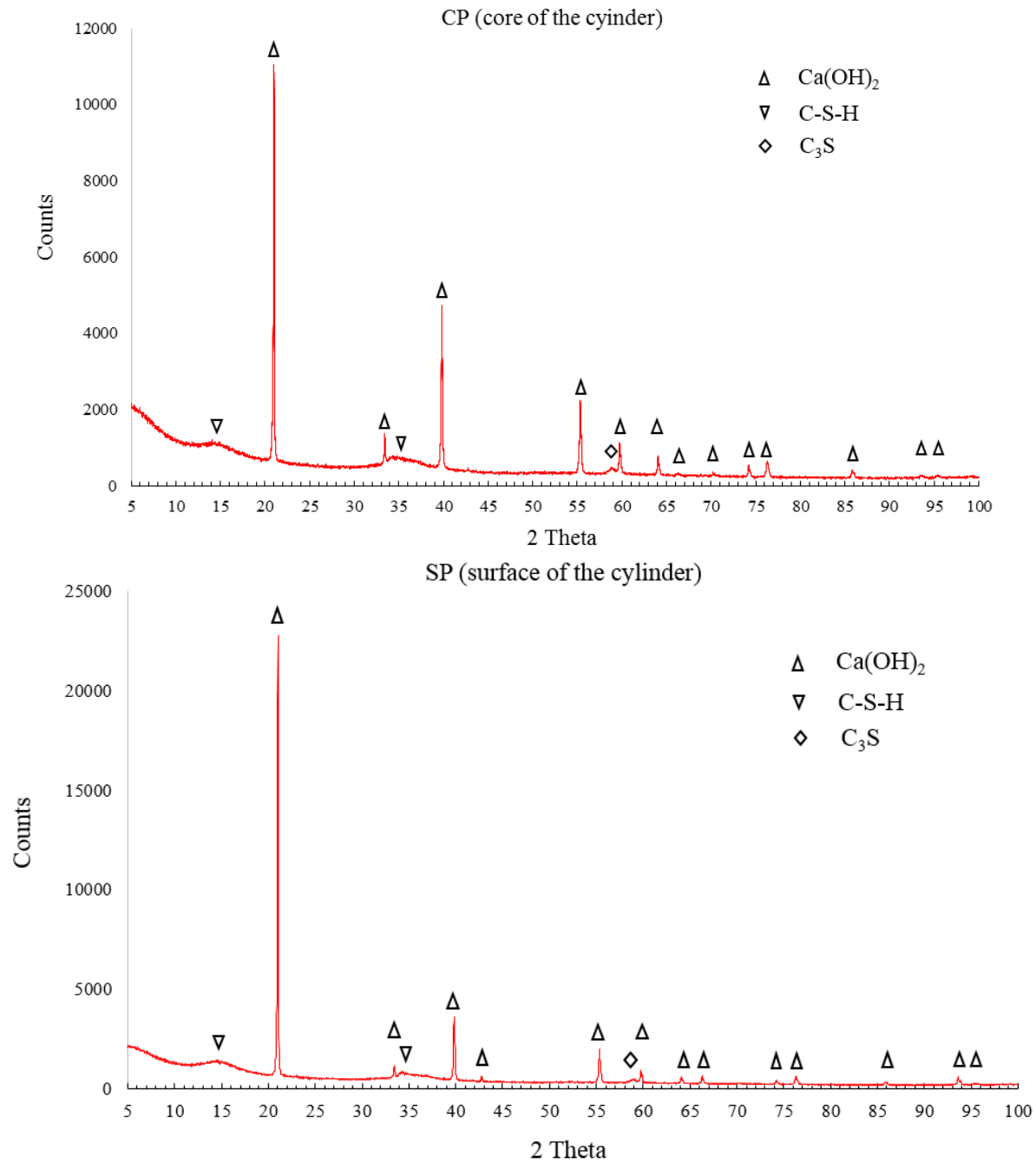

Figure 2: XRD results of $\mathrm{CP}$ (core of the cylinder) and SP (surface of the cylinder) 

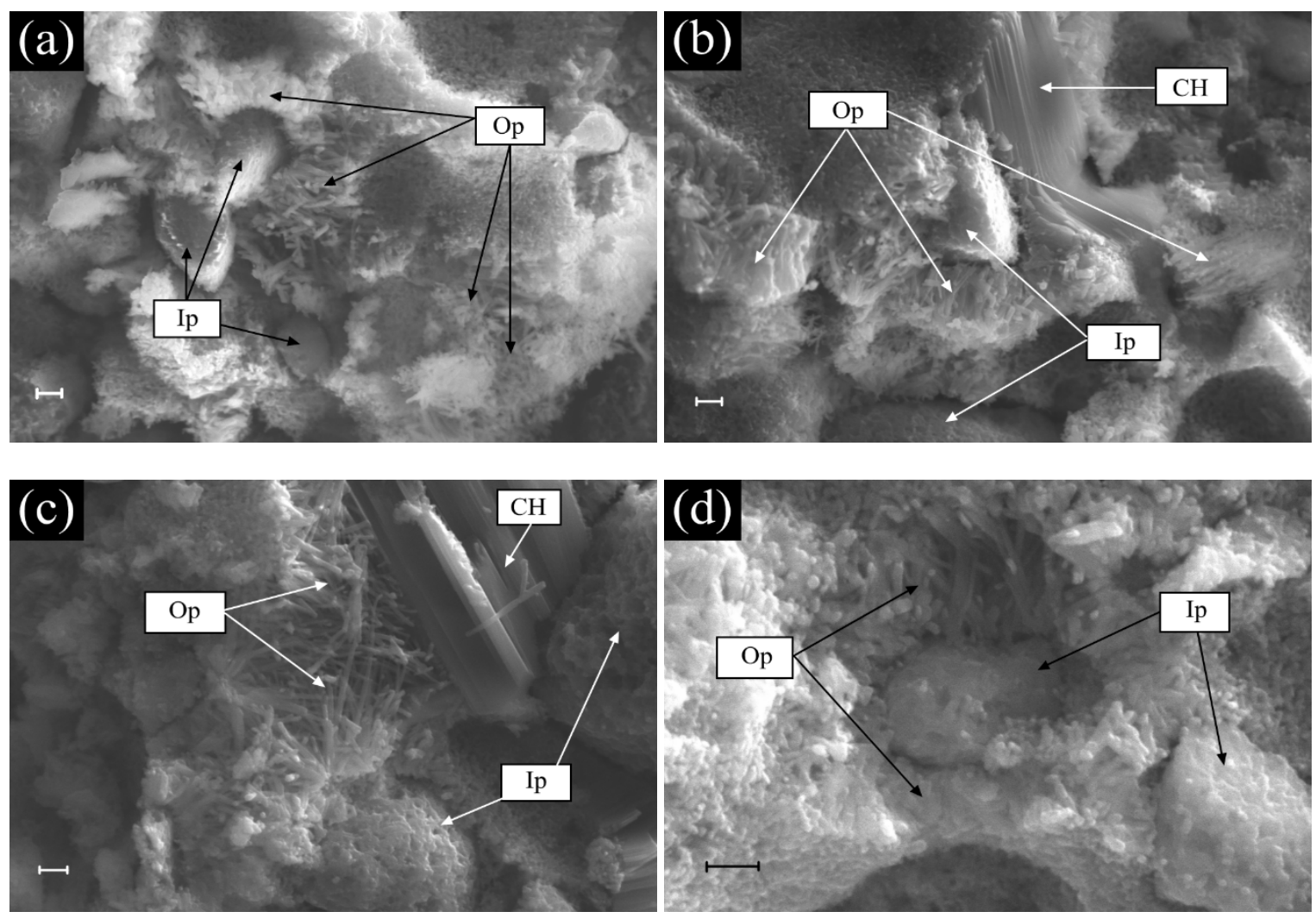

Figure 3: Secondary electron image on different locations in CP (core of the cylinder), bar length $1 \mu \mathrm{m}$ 

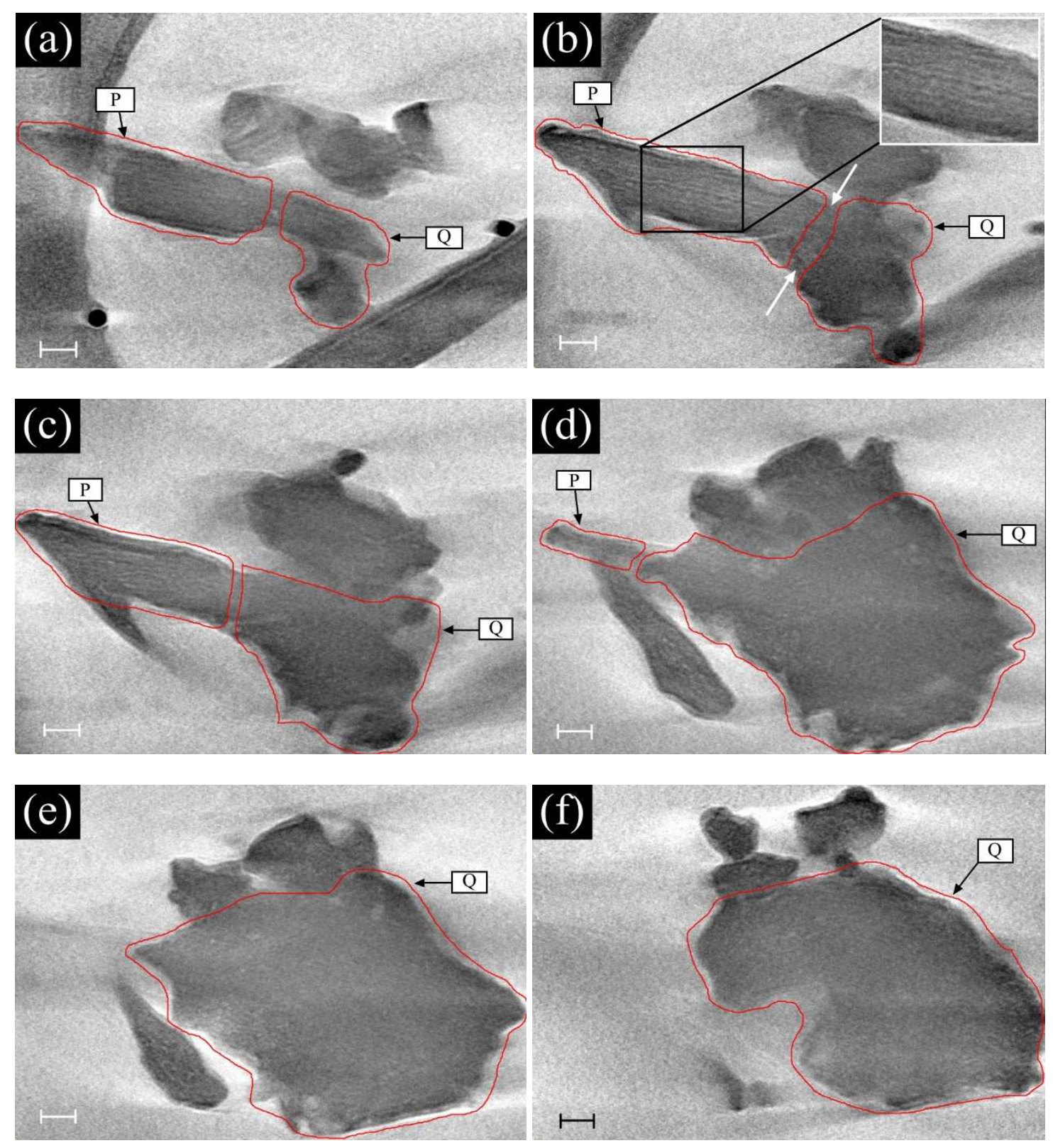

Figure 4: A series of slices from the reconstruction of a particle in $\mathrm{C}_{3} \mathrm{~S}$ paste, which is unidirectionally rotated from (a) to (f); bar length is $20 \mathrm{~nm}$. Area P and Q are, respectively Op and Ip C-S-H respectively. During rotation the feature of area Q increases while that of area $\mathrm{P}$ fades. 


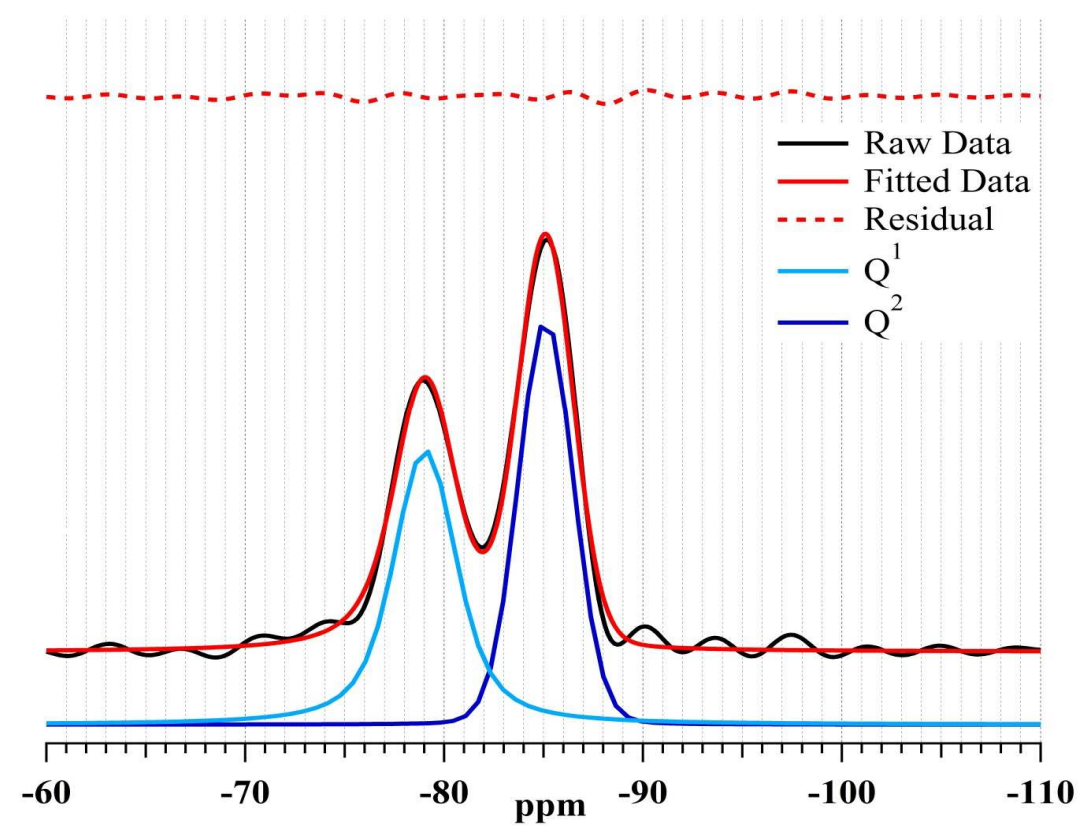

Figure 5: ${ }^{29} \mathrm{Si}$ NMR spectrum of 50-year-old $\mathrm{C}_{3} \mathrm{~S}$ paste, deconvoluted to $\mathrm{Q}^{1}(-79.0)$ and $\mathrm{Q}^{2}(-85.1)$. All y-axis are set to the same intensity. 

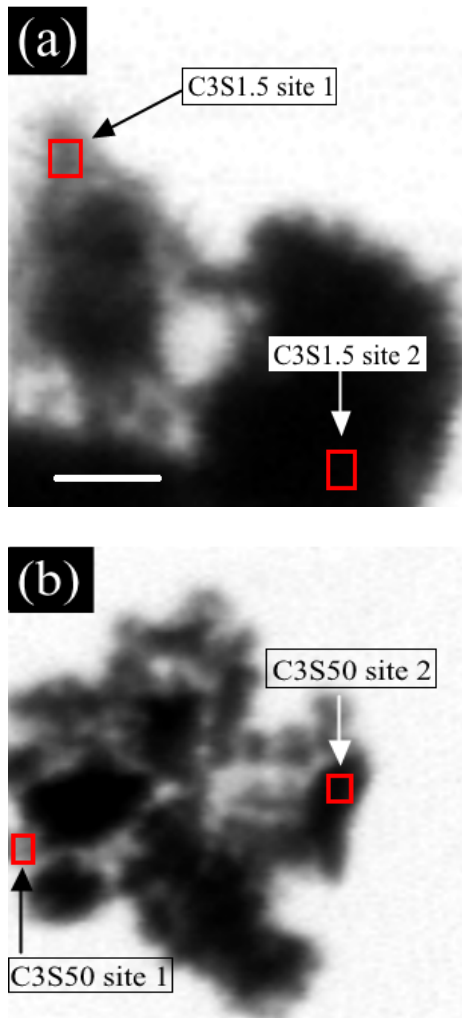

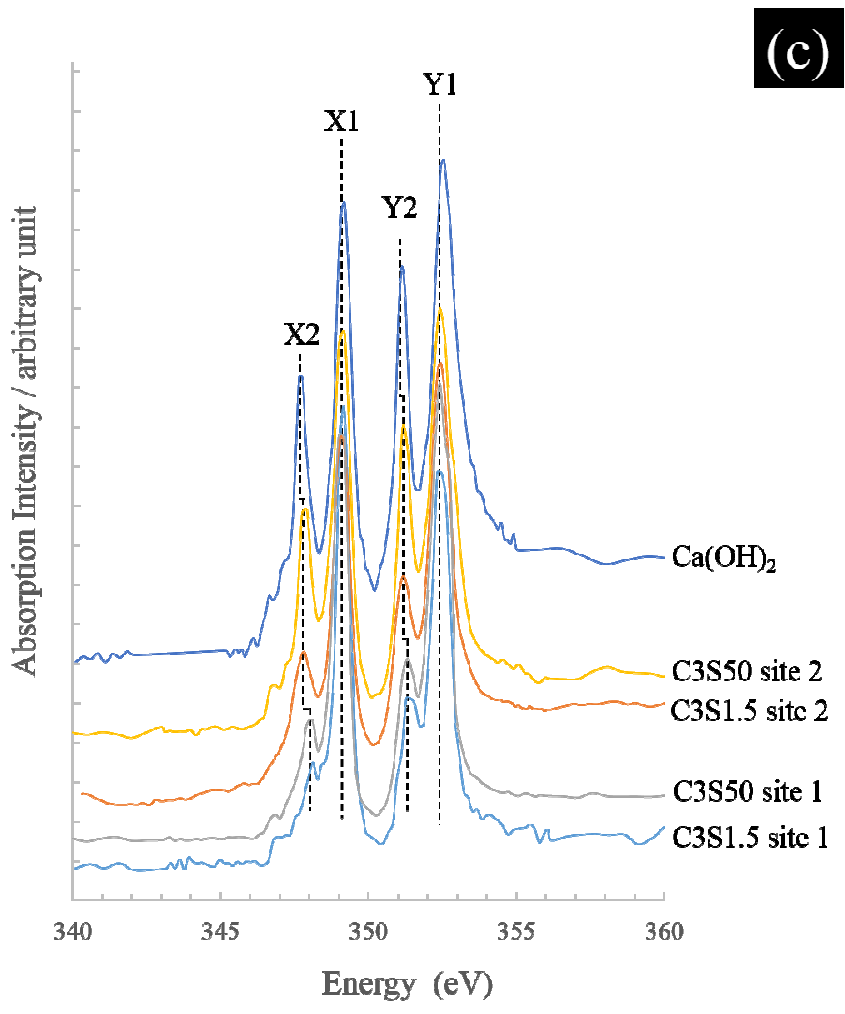

Figure 6: $\mathrm{Ca} \mathrm{L}_{3,2}$-edge, scale bar length 500nm: absorption image of (a) $\mathrm{C}_{3} \mathrm{~S} 1.5$ and (b) $\mathrm{C}_{3} \mathrm{~S} 50$; (c) NEXAFS spectra of hydrated $\mathrm{C}_{3} \mathrm{~S}$ samples, compared with that of pure $\mathrm{CH}$. Spectra of $\mathrm{CH}$ is from [44]. 

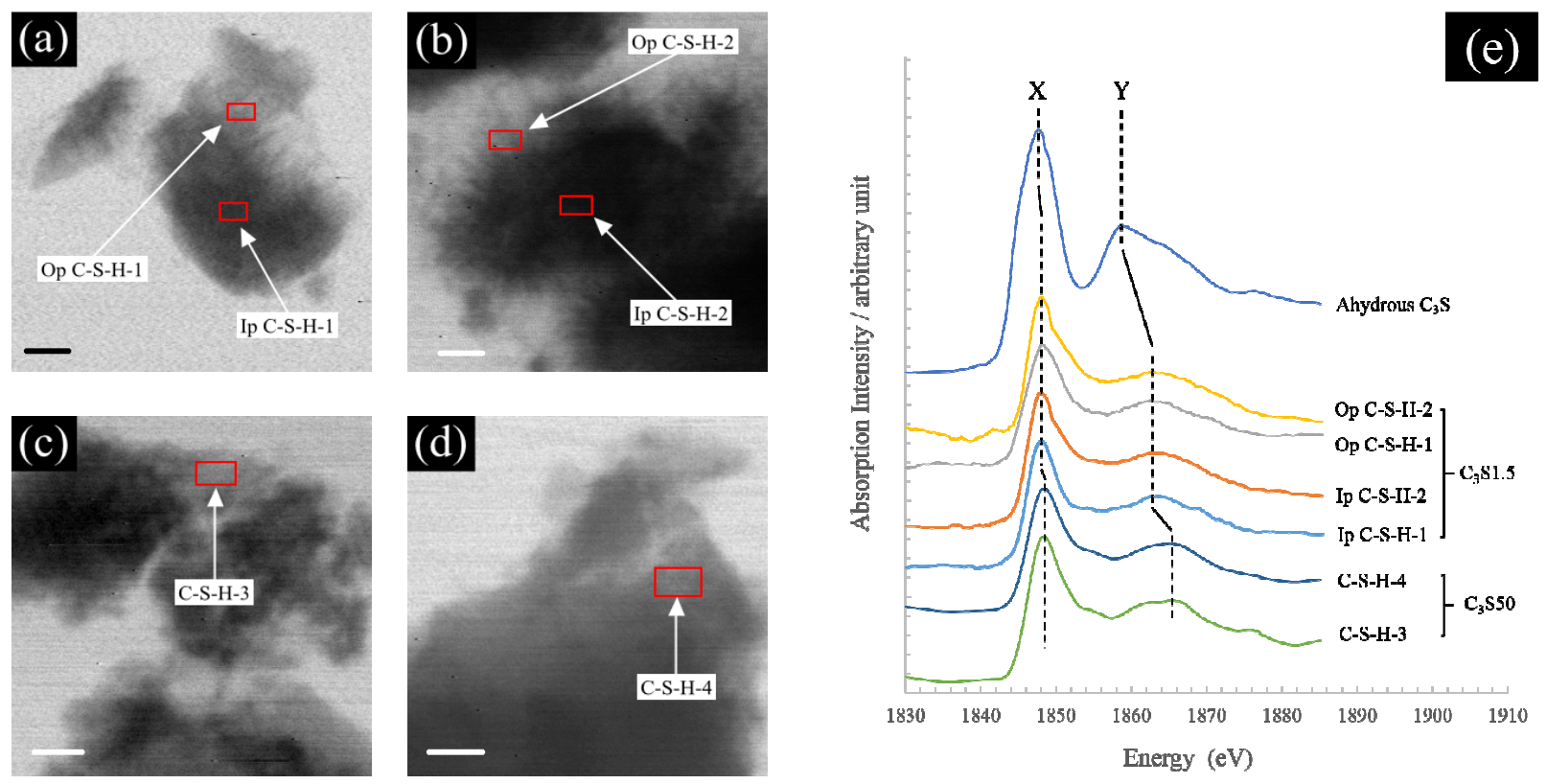

Figure 7: Si K-edge, scale bar length $1 \mu \mathrm{m}$ : (a) (b) absorption image of $\mathrm{C}_{3} \mathrm{~S} 1.5$; (c) (d) absorption image of $\mathrm{C}_{3} \mathrm{~S} 50$; (e) NEXAFS spectra of various locations. 

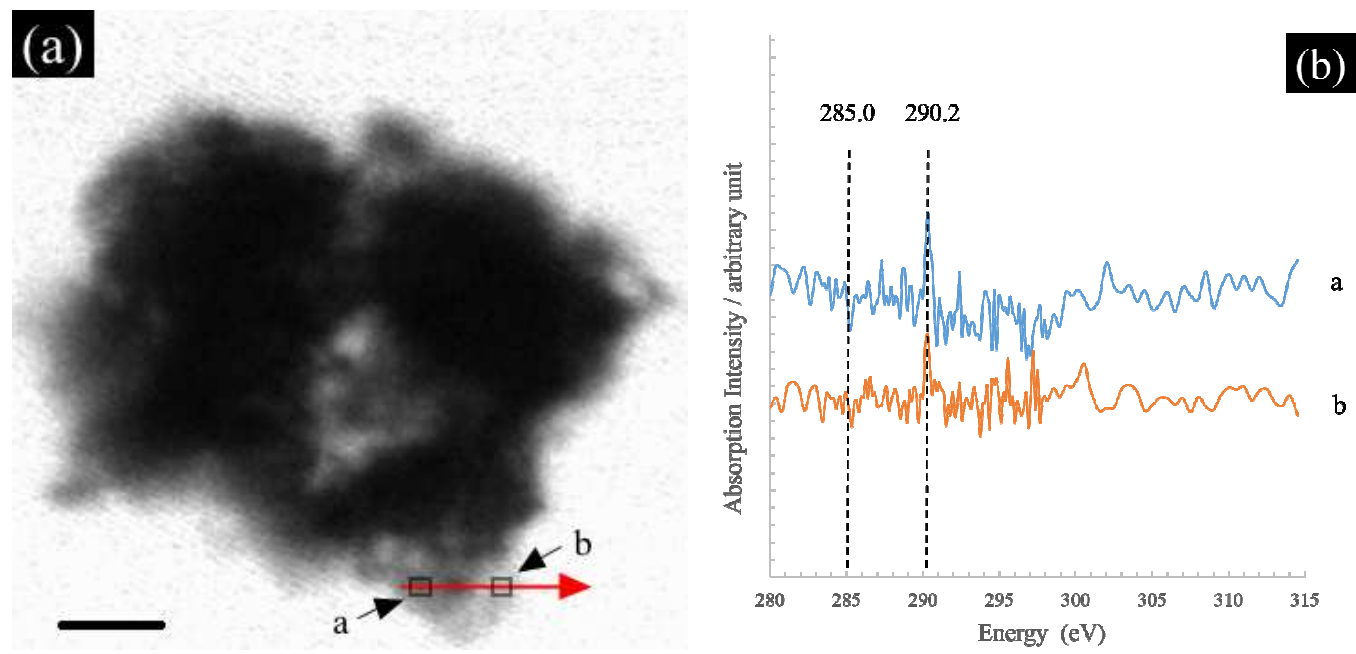

Figure 8: C K-edge, scale bar length $1 \mu \mathrm{m}$ : (a) absorption image, red arrow indicates the route of line scan; (b) NEXAFS spectra of location $a$ and $b$ on the scan route. 

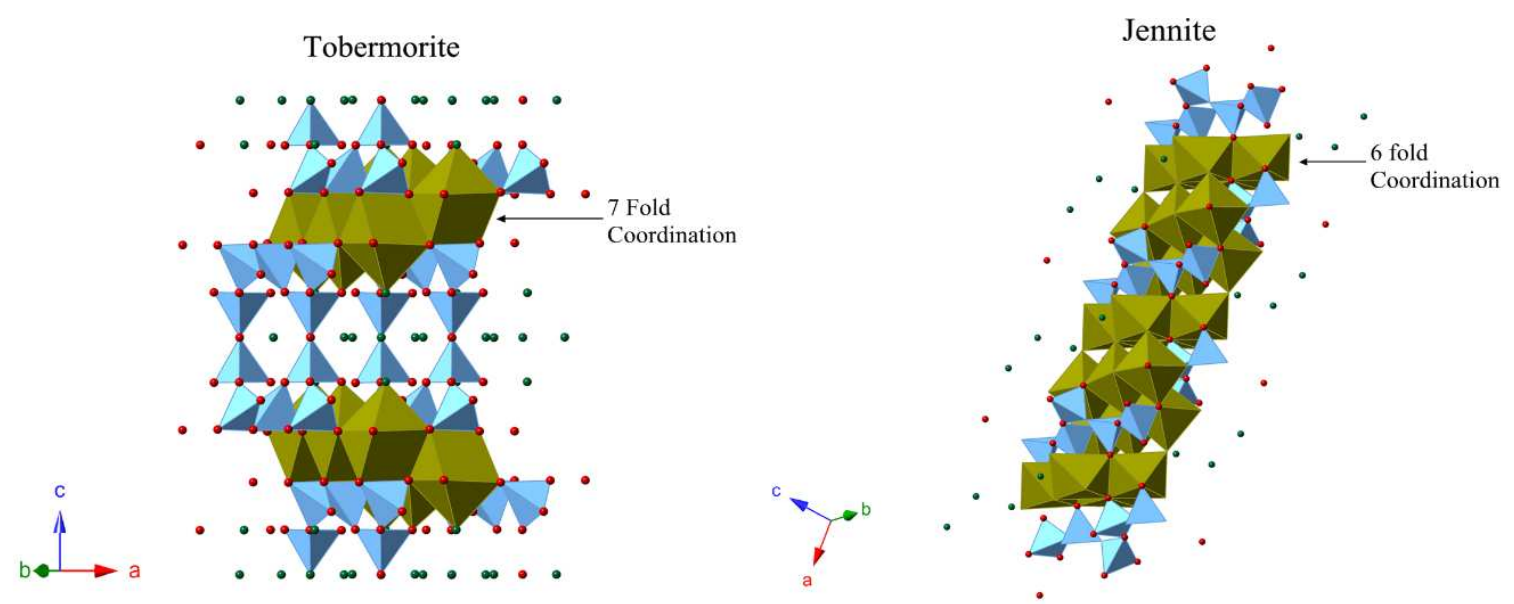

Figure 9: Atomic structure of 11Å-Tobermorite and Jennite [40][41]

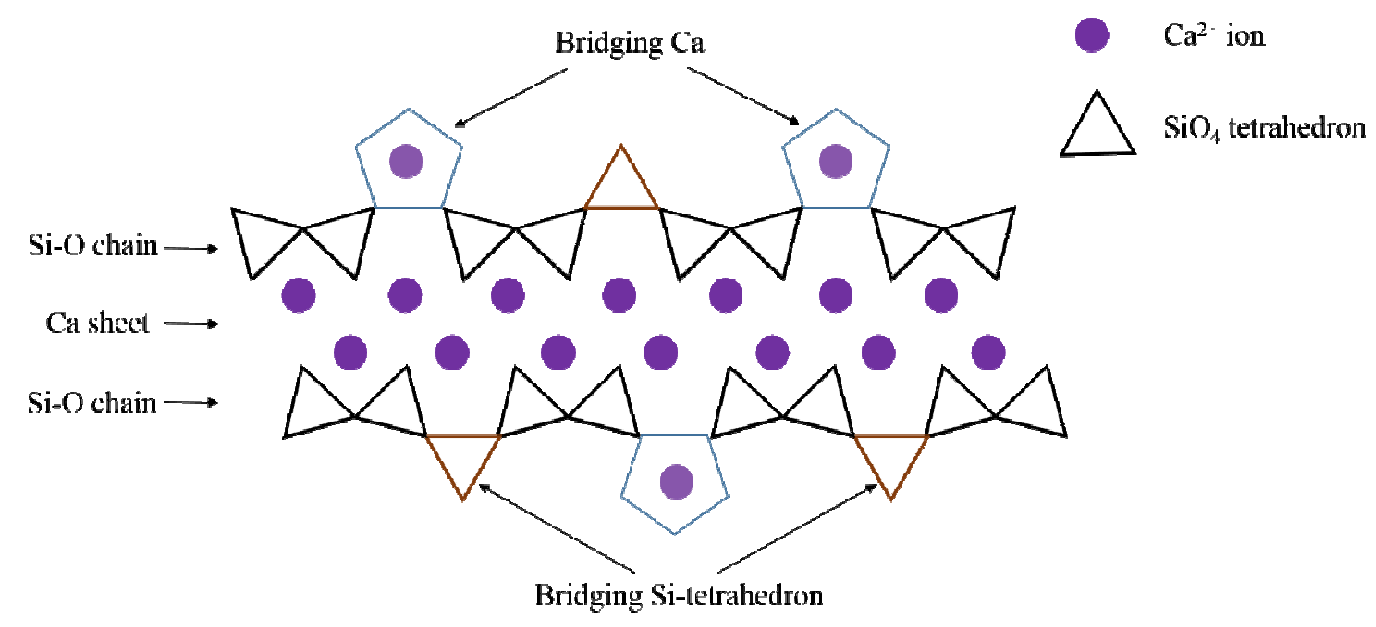

Figure 10: Scheme of short chain in tobermorite-based C-S-H 


\section{Tables}

Table 1: Statistics of EDS data of the 50 -year-old $\mathrm{C}_{3} \mathrm{~S}$ paste

\begin{tabular}{cccc}
\hline Phases & \# of testing points & Average atomic Ca/Si & Standard Deviation \\
\hline Ip C-S-H & 11 & 1.68 & 0.15 \\
Op C-S-H & 6 & 2.02 & 0.15 \\
CH & 3 & 14.12 & 2.41 \\
\hline
\end{tabular}

Table 2: Quantity of Si anions in each environment as a percentage obtained from integration of the peak areas. Data from 12 hours to 26 years are from Rodger [9]

\begin{tabular}{ccccc}
\hline Age & $\mathrm{Q}^{0}$ & $\mathrm{Q}^{1}$ & $\mathrm{Q}^{2}$ & $\mathrm{MCL}$ \\
\hline 12 hours & 89 & 11.0 & 0.0 & 2.00 \\
1 day & 68 & 30.0 & 2.0 & 2.13 \\
7 days & 48 & 43.0 & 9.0 & 2.42 \\
14 days & 33 & 52.0 & 15.0 & 2.58 \\
1 month & 30 & 53.0 & 17.0 & 2.64 \\
3 month & 18 & 62.0 & 20.0 & 2.65 \\
6 month & 14 & 65.0 & 21.0 & 2.65 \\
1 year & 10 & 55.0 & 35.0 & 3.27 \\
2 years & 6 & 52.0 & 42.0 & 3.62 \\
26 years & 0 & 42.0 & 58.0 & 4.76 \\
50 years & 0 & 47.9 & 52.1 & 4.18 \\
\hline
\end{tabular}


Table 3: Peak characters from the Ca L-edge spectra, some data are from [36][37]

\begin{tabular}{cccc}
\hline Compound & $\Delta \mathrm{X} / \mathrm{eV}$ & $\Delta \mathrm{Y} / \mathrm{eV}$ & Symmetry of coordination \\
\hline Pure $\mathrm{CH}$ & 1.4 & 1.4 & \\
$\mathrm{CH}$ in $\mathrm{C}_{3} \mathrm{~S} 50$ (site 2) & 1.3 & 1.3 & Octahedral \\
$\mathrm{CH}$ in $\mathrm{C}_{3} \mathrm{~S} 1.5$ (site 2) & 1.3 & 1.3 & \\
Calcite & 1.2 & 1.3 & \\
Dolomite & 1.3 & 1.3 & \\
Aragonite & 0.8 & 0.8 & Irregular \\
& & & \\
Gypsum & 0.9 & 0.9 & Irregular \\
& & & \\
$\mathrm{C}-\mathrm{S}-\mathrm{H}$ in $\mathrm{C}_{3} \mathrm{~S} 50$ (site 1) & 0.9 & 1.1 & Unknown \\
$\mathrm{C}-\mathrm{S}-\mathrm{H}$ in $\mathrm{C}_{3} \mathrm{~S} 1.5$ (site 1) & 1.0 & 0.9 &
\end{tabular}

Table 4: Energy difference, $\Delta \mathrm{E}$, between minor and major peak at Si K-edge

\begin{tabular}{cccccc}
\hline \multicolumn{2}{c}{ Sample } & $\mathrm{X}(\mathrm{eV})$ & $\mathrm{Y}(\mathrm{eV})$ & $\Delta \mathrm{E}(\mathrm{eV})$ & Hydration time \\
\hline \multirow{6}{*}{$\mathrm{C}_{3} \mathrm{~S} 1.5$} & $\mathrm{C}_{3} \mathrm{~S}$ & 1847.7 & 1858.9 & 11.2 & 0 \\
& Ip C-S-H-1 & 1848.1 & 1860.9 & 12.8 & 1.5 \\
& Ip C-S-H-2 & 1848.1 & 1860.9 & 12.8 & 1.5 \\
& Op C-S-H-1 & 1848.1 & 1861.1 & 13.0 & 1.5 \\
& Op C-S-H-2 & 1848.1 & 1861.1 & 13.0 & 1.5 \\
$\mathrm{C}_{3} \mathrm{~S} 50$ & C-S-H-3 & 1848.3 & 1864.8 & 16.5 & 50 \\
& C-S-H-4 & 1848.3 & 1864.8 & 16.5 & 50 \\
\hline
\end{tabular}

